\title{
HIGH PRESSURE DROPLET BURNING EXPERIUENTS IN REDUCED GRAVITY
}

\author{
Christian Chauveau and Iskender Gökalp \\ Liaboratoire de Combustion et Systèmes Réactifs \\ Centre National de la Recherche Scientiñque \\ 45071 Orleans cedex 2, France
}

\section{Introduction}

Depending on the surrounding flow and thermodynamic conditions, a single droplet may experience several gasification regimes, ranging from the envelope flame regime to pure vaporization (ref. 1). The characteristic times of droplet gasification are largeiy influenced by the surrounding pressure and temperature. Gasification of liquid droplets under high pressure conditions is indeed one of the main phenomena characterizing liquid fueled energy systems. It is also conjectured that droplets initially injected in the high pressure combustion chamber under subcritical temperatures may heat up and attain the supercritical thermodynamic state before their total gasification. Many theoretical and compurational studies have addressed sub- and supercritical droplet vaporization phenomena under spherical symmetry (refs. 2-11) or axisymmetric conditions (refs.12 14), by solving the conservation equations associated with the problem. Most of the contributions take into account the transient effects, the thermodynamic non-idealities and the ambient gas solubility in the liquid phase due to high pressures. Some new approaches based on molecular dynamics are also emerging (ref. 15).

A parametric investigation of single droplet gasification regimes is therefore helpful in providing the necessary physical ideas for sub-grid models used in spray combustion numerical prediction codes. A research program has been initiated at the ICSR to explore the vaporization regimes of single and interacting hydrocarbon (ref. 1) and liquid oxygen droplets (ref. 16) under high pressure conditions. The research program aiso includes the investigation of single and interacting droplets vaporizing in laminar or turbulent, isothermal or heated flows (ref. 17). In parallel to pure liquid droplet studies, bicomponent hydrocarbon droplets are also investigated (ref.18). Droplet interaction effects are explored for the configuration of three droplets in tandem vaporizing in a laminar heated flow (ref. 19). Reduced gravity studies are conducted to reproduce spherical symmetry conditions essentially for burning droplet studies (refs. 1 and 20).

This paper summarizes the status of the LCSR program on the high pressure burning of single fuel droplets; recent results obtained under normal and reduced gravity conditions with suspended droplets are presented. In the work described here, parabolic flights of the CNES Caravelle is used to create a reduced gravity environment of the order of $10^{-2} \mathrm{go}$. For ail the droplet burning experiments reported here, the suspended droplet initial diameters are scattered around $1.5 \mathrm{~mm}$; and the ambient air temperature is $300 \mathrm{~K}$. The ambient pressure is varied between $0.1 \mathrm{MPa}$ and $12 \mathrm{MPa}$. Four fuels are investigated : methanol $(\mathrm{Pc}=7.9 \mathrm{MPa})$, n-heptane $(\mathrm{Pc}=2.74 \mathrm{MPa})$, n-hexane $(\mathrm{Pc}=3.01 \mathrm{MPa})$ and $\mathrm{n}$ octane $(\mathrm{Pc}=2.48 \mathrm{MPa})$. 


\section{Description of the experimental techniques}

\section{High pressure droplet gasification facility}

Droplet gasification experiments under stagnant and variable pressure conditions are performed in a specially designed facility : High Pressure Droplet Gasification Facility (HP-DGF). The HP-DGF is designed to investigate the gasification regimes of suspended or free-floating droplets under variable pressure conditions, up to $12 \mathrm{MPa}$. Low pressure droplet burning experiments can also be performed. This facility can be used during the parabolic flights of an aircraft. This apparatus has been fully described previously (ref.1). For high pressure droplet burning experiments, an improved version of the injection system and a heated coil for ignition are used. The coil is located about 15 droplet diameter below the suspending fiber and is used to heat the air in the vicinity of the droplet. The coil heating current is shut down when droplet autoignition is attained. The sequence of injection and ignition operations is computer controlled. The results presented in this paper are obtained with droplets suspended on a quartz fiber of $0.2 \mathrm{~mm}$ with an enlarged extremity of $0.4 \mathrm{~mm}$ diameter.

\section{Diagnostics}

The principle diagnostic systems we are using are based on the visualization of the droplet burning phenomena. Suspended droplets are backlighted; this provides the necessary contrast for direct threshold definition. The recording equipment is based on the high speed video camera, Kodak-Ektapro 1000 , which can record up to 1000 full frames per second, and allows detailed analysis of droplet burning. The Ektapro 1000 Motion Analyzer's live, real-time viewing makes possible to follow the investigated phenomena frame per frame. A second camera has been added to the Kodak-Ektapro 1000 system. to be able to observe simultaneously the droplet and the flame with respective appropriate magnification rates. The digitized images from the Ektapro system are transferred to a microcomputer where the image analyses are performed. For the details of the image analysis, refs. 1 and.16 can be consulted.

\section{Results and discussion}

Burning droplet experiments have been conducted both under normal gravity conditions and under reduced gravity conditions. An example of the residual gravity level recorded during a parabolic flight experiment is given on Fig. 2. The figure shows the time variation of the gravity level synchronized with the camera acquisition, during the 20 seconds of the microgravity period. On this sequence, the average gravity level corresponding to the actual droplet burning time $(0.69 \mathrm{~s}$ for a n-octane droplet burning at 8 $\mathrm{MPa}$ ) is $210^{-2} \mathrm{~g}_{0}$.

Figure 3 presents the time histories of the normalized squared droplet diameter versus normalized time for methanol droplets burning under nomal gravity. For the pressure range explored $(\mathrm{Pr}=0.9)$, the droplet projected surface area regresses quasi-linearly with time, which authorizes the determination of an average burning rate $\mathrm{K}$. A similar behaviour is also observed for the experiments conducted under reduced gravity. The average burning rates determined under normal and reduced gravity are compared in Fig. 4 for a pressure range extending up to $\mathrm{Pr}=1.15$. As expected, the reduced gravity $\mathrm{K}$ values are lower than the normal gravity values; both increase continuously with pressure. The strong increase of $\mathrm{K}$ with pressure above $\operatorname{Pr}=0.8$ under normal gravity remains unexplained. The results obtained with $n-$ heptane droplets are shown on Fig. 5. As the critical pressure of $n$-heptane is lower, $\operatorname{Pr}$ values larger than 4 is obtained in the experiments in microgravity. The lowering of the pressure effect above the 
critical pressure is clearly observed. The results obtained in microgravity with the four fuels tested are shown on Fig. 6. On this figure, the burning rate at a given pressure is normalized by its value at the critical pressure. The scattering of the experimental values become significant for high pressures, while a single behaviour characterizes the subcritical domain. An interesting feature of these results is that we did not observe a maximum burning rate around the critical pressure, as was observed by Sato in ref. 21. Figure 7 shows the corresponding burning times for a droplet of $1 \mathrm{~mm}$ initial diameter versus the reduced pressure. The subcritical domain is characterized by a strong decrease of the burning time, which seems to be stabilized during the whole supercritical domain. In ref. 21 , a minimum of the burning time near the critical pressure was clearly observed.

The main differences between the two experiments are related to the reduced gravity levels; the experiments of ref. 21 were conducted by using drop towers, where the residual gravity level is much less. The increase of the burning time observed in ref. $2 \mathrm{I}$ in the supercritical domain can be explained by the onset of a diffusion controlled regime after the vanishing of the gas-liquid interface. In the present experiments, the residual gravity induced natural convection is enhanced with increasing pressure; also in the supercritical domain, the reduction of the surface tension makes the dense gas phase much more sensible to convection effects. All together these two effects may therefore explain the present experimental observations. In order to quantify these predictions, an attempt to introduce a Grashof number correction is presently under development (ref. 22).

\section{Summary and future work}

In the work described here, emphasis is put on recent results obtained in high pressure droplet burning experiments conducted both under normal gravity and during the parabolic flights of the CNES Caravelle which creates a reduced gravity environment of the order of $10^{-2} \mathrm{go}$. The combination of high pressure droplet buming experiments with reduced gravity is crucial in order to reduce the pressure enhanced natural convection effects and also to extend the applicability of the fibre suspended droplet technique when the surface tension decreases due to the closeness of thermodynamic critical conditions. The experimental results presented in this paper show a decrease of the droplet burning time with pressure in the subcritical domain. The minimum burning time observed by other investigators around the critical pressure was not found in this study for the four fuels investigated. This may be attributed to the pressure enhanced natural convection effects due to the residual gravity during parabolic flight experiments.

The investigation of high pressure effects will continue to be the main focus of the future LCSR work on droplet gasification regimes. The supercritical regime will be approached in the pure vaporization experiments with the help of a new version of the HP-DGF which is under construction; it will allow to increase the temperature as well as the pressure of the ambient medium. This apparatus will be used to investigate the vaporization and burning of mono and multicomponent fuel droplets in high pressure and high temperature conditions and also to compare normal gravity and reduced gravity experiments to infer natural convection effects. An electrodynamic balance is developed and will be added to the apparatus. It will allow to conduct supercritical vaporization experiments under normal gravity conditions. Parabolic flights will be continued to be used for suspended droplet experiments. A new high pressure droplet burning module will be developed to be used during sounding rocket experiments with ESA. 
This work is supported by the CNRS/CNES joint research program on "Transport phenomena in reduced gravity" and by the European Space Agency Microgravity Program. The continuous support of CNES (program monitor Dr. B. Zappoli) and of ESA (program monitor Dr. H.U. Walter) is greatly appreciated.

\section{$\underline{\text { References }}$}

1. Chauveau, C, Chesneau, X, and Gökalp, I., ALAA Paper No. 93-0824, 1993

2. Spalding, D.B., ARS J. 29, 828-835, 1959

3. Wieber, P;R., AIAA J. 1, 2764-2770, 1963

4. Manrique, J.A. and Borman, G.L. Int. J. Heat and Mass Transfer 12, 1081-1095, 1969

5. Rosner, D.E. and Chang, W.S., Combust. Sci. Technol. 7, 145-158, 1973

6. Kadota, T., and Hiroyasu, H., Bull. JSME 19, 1515-1521, 1976

7. Litchford, R.J., and Jeng, S.M., AIAA Paper No. 90-2191, 1990

8. Hsieh, K.C., Shuen, J.S., and Yang, V.,Combust. Sci. Technol. 76, 111-132, 1991

9. Curtis, E.W., and Farrell, P.V.,Combust. Flame 90, 85-102, 1992

9. Delplanque, J.P., and Sirignano, W.A., Int. J. Heat Mass Transfer 36, 303-314, 1993

10.Yang, V., and Lin, N.N. "Vaporization of liquid oxygen droplets in supercritical hydrogen environments", submitted to Combust. Sci. Technol., 1993

11. Jia H., and Gogos, G., Int. J. Heat Mass Transfer 36, 4419-4431, 1993

12. Delplanque, J.P., and Sirignano, W.A. Atomization and Sprays, vol. 4, pp. 325-349,1994

13. Sirignano, W.A., Delplanque, J.P., Chiang, J.H., and Bahtia, R., "Liquid propellant droplet vaporization : a driving mechanism for rocket combustion instability", paper presented at the First International Symposium on Liquid Rocket Combustion Instability, The Pennsylvania State University, January 18-20, 1993

14.Hsia, C.C., and Yang, V.,"Lox droplet vaporization in a supercritical forced convective environment", paper presented at the Fifth Annual Symposium of the Propulsion Engineering Research Center, The Pennsylvania State University, University Park, PA, September 8-9, 1993

15. Long, L.N., Micci, M.M., and Wong, B.C.,"supercritical droplet evaporation modelled using molecular dynamics on parallel processors", paper submitted for presentation at the 30th Joint Propulsion Conference, Indianapolis, IN, June 27-29, 1994

16. Chesneau, X., Chauveau C., and Gökalp, I., AIAA Paper No. 94-0688, 1994

17. I. Gökalp, C. Chauveau, O. Simon and X. Chesneau, Combust. Flame 89, 286-298, 1992. see also Birouk, M., Chauveau, C., Sarh, B., Quilgars, A., and Gökalp, I., Turbulence effects on the vaporization of monocomponent single droplets. Proceedings of the 11 th European Conference of IILASS-Europe on Atomization and sprays, Nümberg, March 21-23, 1995, pp. 457-466.

18. Gökalp, I., Chauveau, C., Berrekam, H., and Ramos-Arroyo,N.A., Atomization and Sprays, vol. 4, pp. 661-676, 1994

19. Ramos-Arroyo, N.A., Chauveau, C., and Gökalp, I., "An experimental study of three interacting vaporizing fuel droplets in a forced convective laminar flow", presented at the Sirth ICLASS, Rouen, July 18-22, 1994, also submitted to Atomization and Sprays

20. Chauveau, C., Chesneau, X., and Gökalp, I., High pressure vaporization and burning of methanol droplets in reduced gravity. Adv. Space Res. Vol. 16, No. 7, pp. (7)157-(7)160, 1995

21. Sato, J., Studies on droplet evaporation and combustion in high pressures, AIAA paper 93-0813, 1993

22. Chesneau, X, PhD Thesis, ,University of Orléans, 1994 


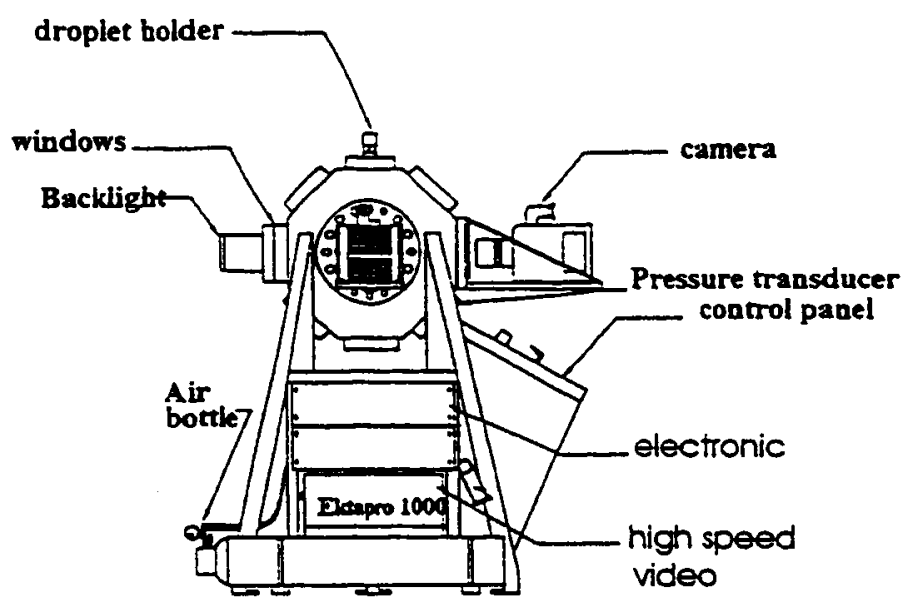

Figure 1 : Droplet Burning Facility (DBF-HP)

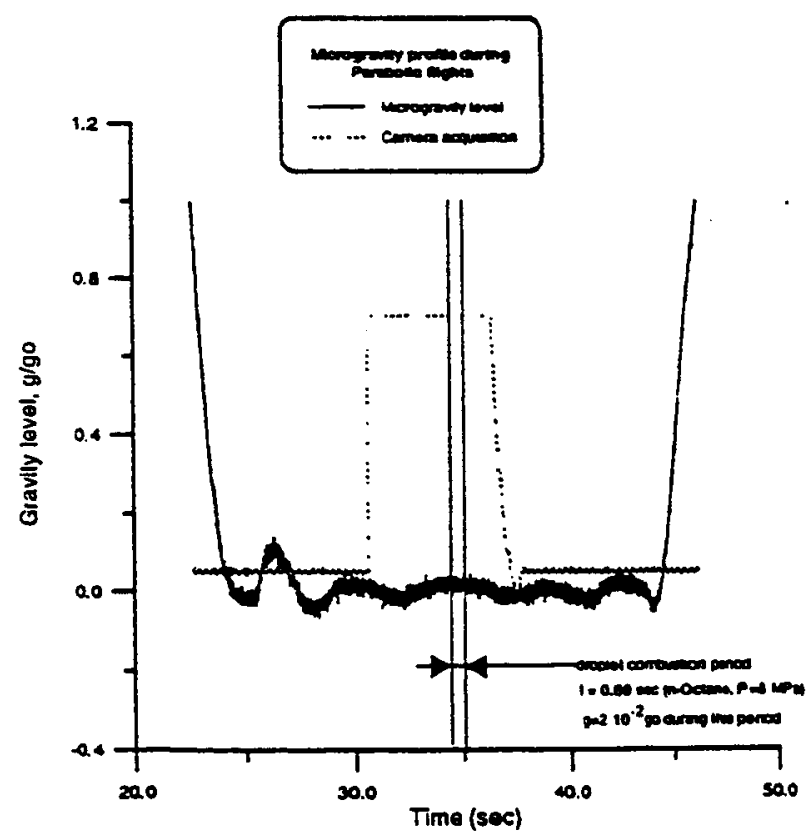

Figure 2 : Microgravity level versus time

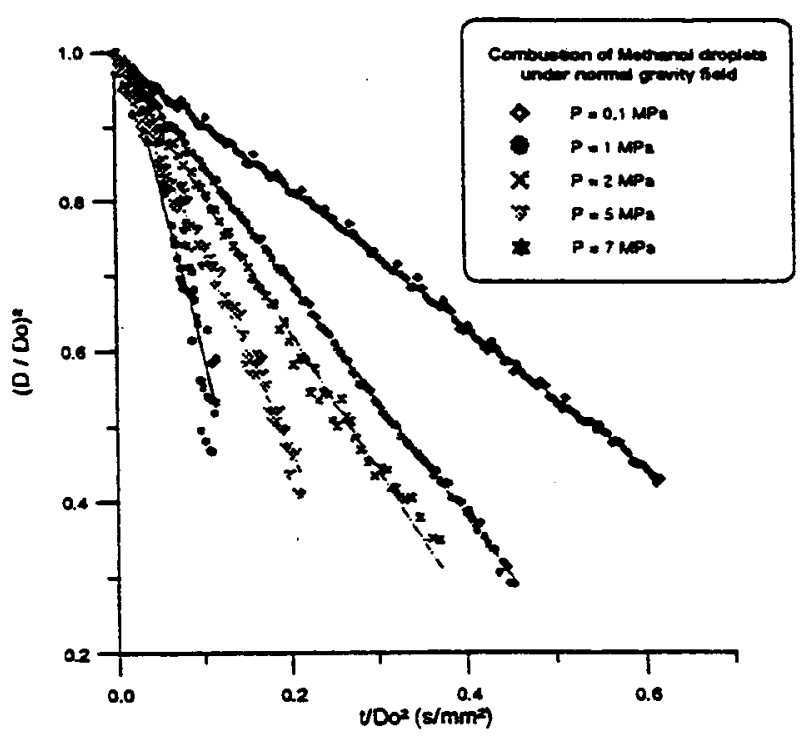

Figure 3 : Evolution of the normalized squared droplet diameter versus normalized time 


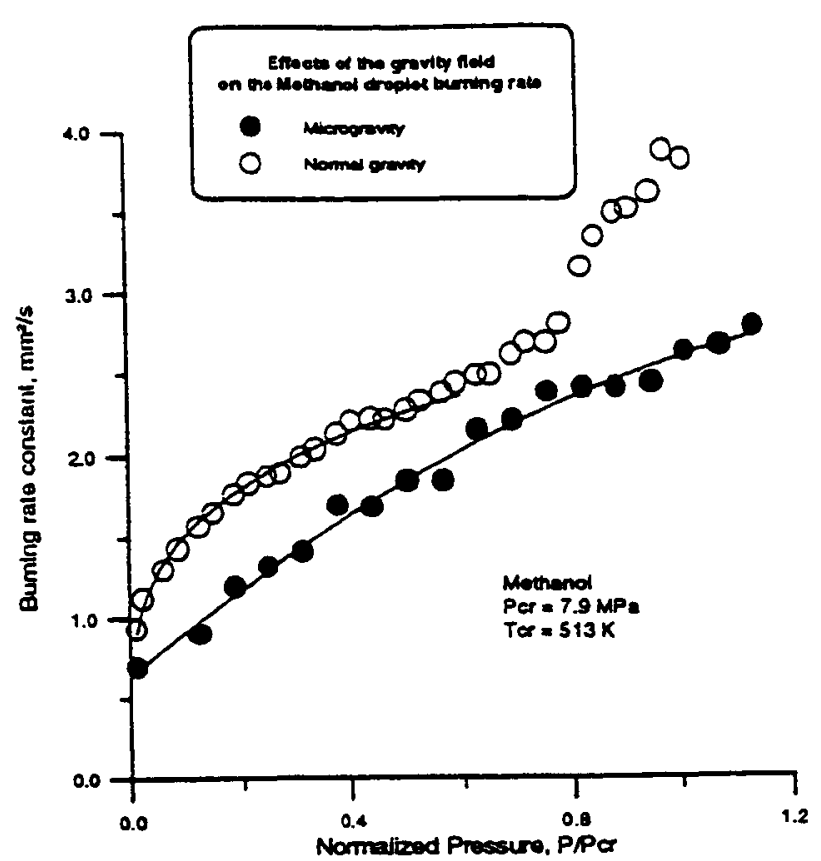

Figure 4 : Evolution of the burning rate constant versus normalized pressure.

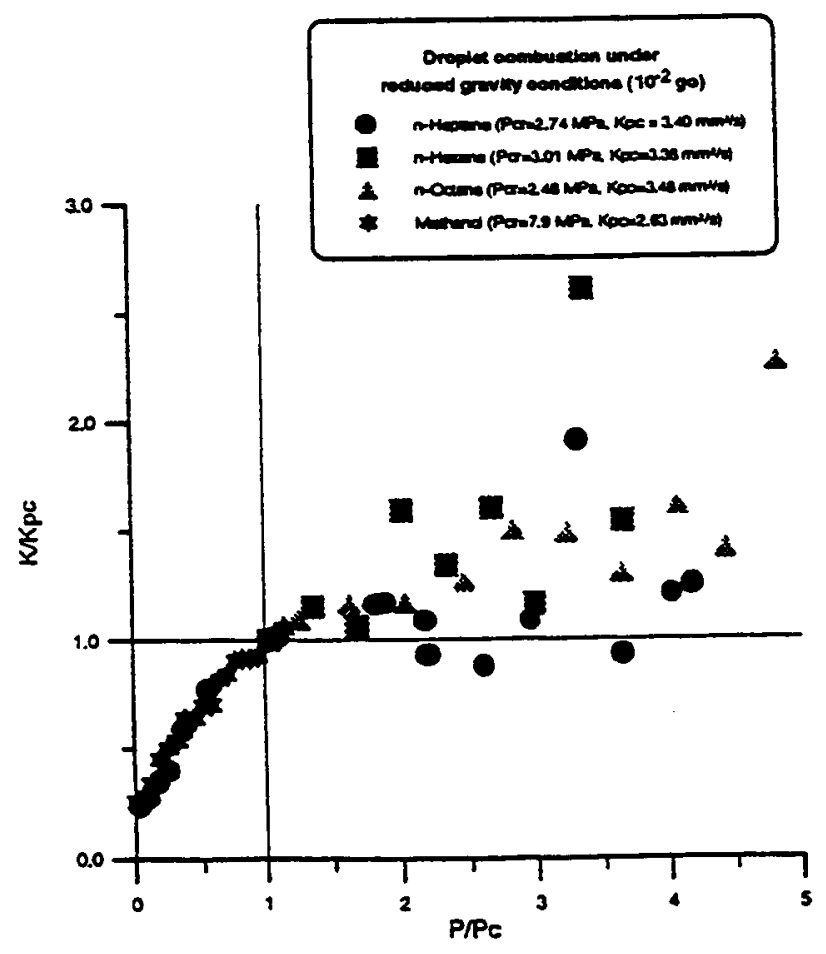

Figure 6 : Evolution of the normalized burning rate constant versus normalized pressure

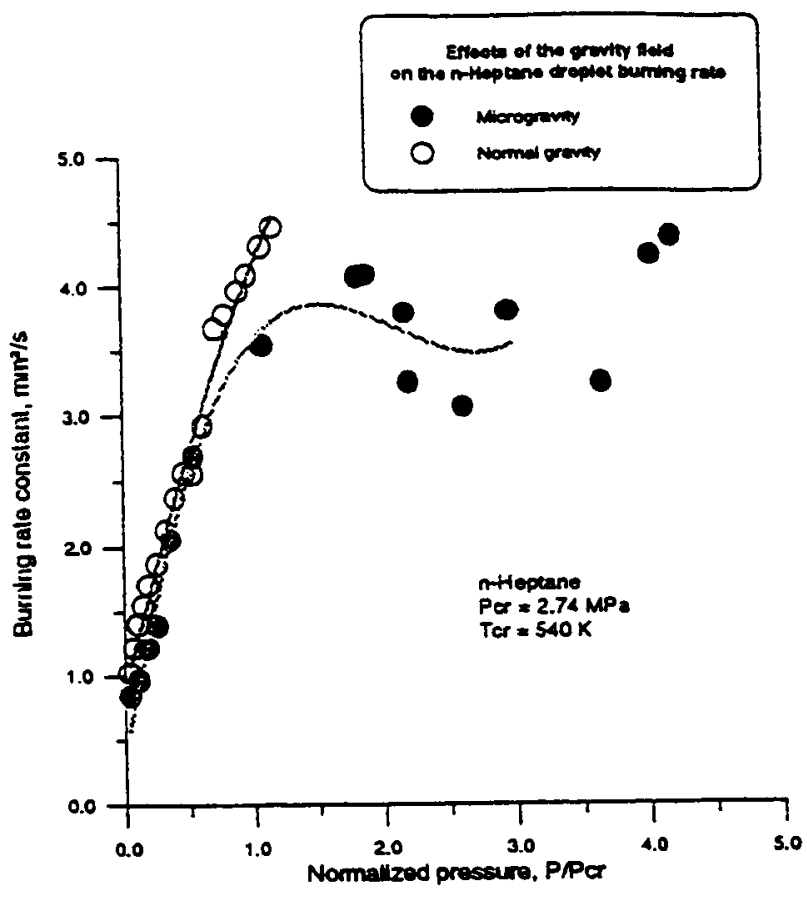

Figure 5 : Evolution of the burning rate constant versus normalized pressure.

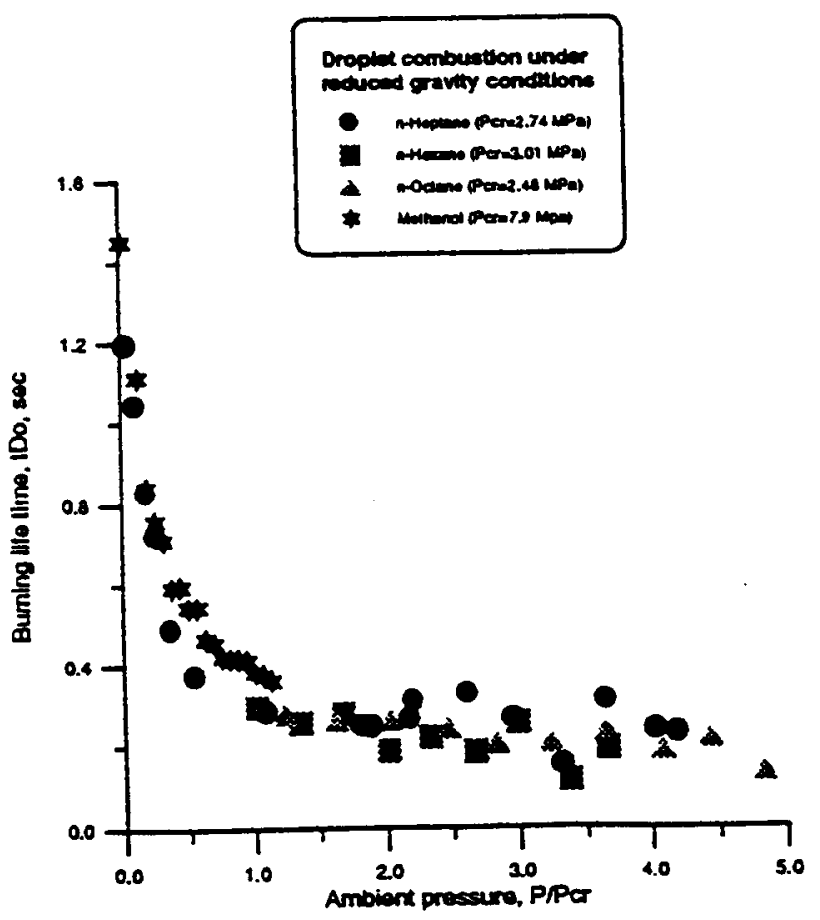

Figure 7 : Evolution of the normalized burning life time versus normalized pressure 